\title{
A Criação de Animações de Mecanismos de Reações Orgânicas como Método de Ensino
}

\section{Lucas Sobral Marques da Conceição ${ }^{1}$, Marcia Vivancos Mendonça², João Pedro Simon}

Farah $^{* 3}$

${ }^{1}$ Universidade Federal do Rio Grande do Sul

${ }^{2}$ Escola Estadual Loureiro Jr.

${ }^{3}$ Instituto de Química da Universidade de São Paulo

* Autor para correspondência: jpsfarah@usp.br

\section{RESUMO}

Visualização científica é uma técnica bem conhecida para ilustrar graficamente dados obtidos de trabalho científico. A criação de imagens maravilhosas e sua animação combinando ciência e artes visuais inspiram atenção e curiosidade em assuntos de alta complexidade. Ao longo do tempo, desenvolvemos um modelo para estudar mecanismos de reações químicas usando visualização científica, para alunos de ensino médio. A demonstração de um experimento em tempo real in vitro é seguida por uma discussão de como, quando e por que átomos são rearranjados em novas moléculas dos produtos. Colocam-se assim as questões científicas, e a motivação para respondê-las emerge da criação de uma animação 3D baseada nas variações das superfícies de densidade eletrônica dos componentes do sistema, indo dos reagentes aos produtos. As questões são apresentadas no contexto de um problema científico, e não para obter uma resposta a um mecanismo específico. Elas emergem da fusão dos mecanismos bem estudados na literatura com os trabalhos computacionais e observações feitas nos experimentos. A animação resultante é pura magia, e assuntos como cinética e termodinâmica de reações químicas são colocados para estudo de maneira gradual e simples. Um semestre normal de atividades pode produzir resultados satisfatórios, independentemente do conhecimento prévio desses assuntos. Adicionalmente, o modelo promove o contato com alguns dos fundamentos de Química Quântica e com algumas técnicas básicas de modelagem molecular. Um dos objetivos alcançados pelo método é a consolidação de um paladar científico, de uma intuição e um apreço grande pelo bom senso, muito úteis à vida científica. Também podemos enumerar como resultados: 1) a importância do contato com o fenômeno real, não importando sua complexidade; 2) o uso da visualização de conceitos abstratos é sempre melhor que só a matemática; 3) não há contraindicações.

Palavras-Chave: Visualização Científica; Animação; Termodinâmica; Cinética; Densidade Eletrônica.

\begin{abstract}
Scientific visualization is a well-known technique to graphically illustrate data from scientific work. The creation of dramatic images and their animation which combines science and the visual art can inspire attention and curiosity for complex subjects. Over the time we developed a model to study chemical reaction mechanism using scientific visualization for high school level students. The demonstration of a real time im vitro experiment is followed by a discussion of how, when and why atoms are rearranged in the new molecules of the products. A scientific question is stated, and motivation for answering emerges from the creation of a 3D animation based on the changes of electronic density molecular surfaces, going from reactants to products. The question is presented in the context of a scientific problem and not as an answer to specific mechanism proposals. We consider questions raised by well-established knowledge in the literature and use it to address questions suggested by the observation of both in vitro and in silico processes. The animation itself is pure magic and subjects such as kinetics and thermodynamics of chemical reactions are addressed in a gradual manner. One semester of regular activity can produce satisfactory results, very independently of previous knowledge in that matter. This model allows comprehensive contact with some basic principles of quantum chemistry and molecular modeling techniques. One of the main goals achieved were to develop some scientific feeling and a kind of intuition based on good sense, very useful in the scientific work. The other observations are: 1) the importance of real experiments no mater its complexity degree; 2) visualization of abstract concepts is always better than mathematics only; 3) there are no contraindications.
\end{abstract}

Keywords: Scientific Visualization; Animation; Thermodynamics; Kinetics; Electronic Density. 


\section{Introdução}

A oportunidade de uma reflexão sobre o ensino de Química Orgânica é extraordinária, já que o tema escolhido pelo comitê organizador para a abertura do Simpósio Nacional da ACS de 2016 foi: "Is there a crisis in organic chemistry education?" (HALFORD, 2016). Esse é exatamente o tema do trabalho de pré-iniciação científica (alunos de ensino médio de escolas públicas) que o grupo desenvolve há cerca de cinco anos.

A urgência do assunto também pode ser avaliada pelas considerações do professor Heinrich Hauptmann (ao lado de Heinrich Rheimboldt, um dos fundadores da pesquisa química no país) no seu livro publicado há 62 anos (HAUPTMANN, 1955), aconselhando a adoção de um enfoque quântico no ensino de Química, especialmente a orgânica. Trata ali sobre a necessidade do uso da teoria de orbitais moleculares para entender os mecanismos de reações orgânicas, propostos genialmente por Christopher Ingold (1934, p. 225). Essa iniciativa de Hauptmann foi, portanto, um reconhecimento de que a mecânica quântica deveria ser valorizada, levando à química do século XX e saindo finalmente do século XIX (FARAH \& RABÓCZKAY, 1998). Em 1955, sem a agilidade dos meios de comunicação atuais, é surpreendente que o professor Hauptmann já estivesse inteirado dos resultados de Ingold sobre o mecanismo de substituições nucleofílicas, de 1953 (INGOLD, 1953) e tenha editado um livro em português sobre o assunto apenas dois anos depois. Essa proeza contrasta muito com a estagnação dos cursos de Química oferecidos atualmente, principalmente devido a uma simplificação imposta pelas dificuldades matemáticas dos alunos!

Acreditamos por hipótese que essa crise no ensino de Química Orgânica vem do fato de que os avanços científicos são perceptíveis pelas pessoas, leigas ou não. Desse modo, um assunto tratado de modo simplificado, cientificamente naif, é imediatamente percebido e cerebralmente arquivado como de baixa relevância e interesse. Esse cenário é corroborado por recentes pesquisas usando imagens de ressonância magnética cerebral em que um input complexo como uma palavra desconhecida desencadeia intensa atividade cerebral em relação ao discurso simplista do dia a dia. Embora a fisiologia desses processos seja ainda controversa, admite-se que o estímulo seja o caminho para o desenvolvimento cerebral.

Atualmente ainda persiste em grande parte dos que se dedicam ao ensino de Química Orgânica - professores e escritores de livros - uma espécie de simplificação do complexo em nome de uma "didática" bastante discutível.

O resultado, a nosso ver, cria uma lacuna entre o conhecimento da estrutura atômica e molecular baseado na Física quântica e a pobre descrição das reações orgânicas e seus mecanismos através de raciocínios qualitativos mal definidos e revestidos de uma aura mística. Em que pesem a existência dos tratamentos quânticos nos livros de Química Orgânica básica e o fato de que cerca de 60-70\% das publicações apresentam interpretações baseadas em cálculos, o uso desse material para aprendizado não passa da apresentação breve nem exercita seu uso ao longo dos estudos das reações e de seus mecanismos.

O principal argumento para a persistência desse enfoque antigo continua a ser uma premissa falsa de que os alunos têm dificuldades nos assuntos matemáticos (ROQUE, 2011, p. 19).

Por outro lado, a observação experimental de uma reação química ocorrendo em tempo real é um exercício de grande complexidade, como sói acontecer com a observação científica em geral. Uma característica fundamental da observação é a quantidade de conhecimento adquirido a priori ao evento, uma espécie de preconceito que torna a observação tendenciosa. Assim, sabe-se que pessoas sem nenhum conhecimento de determinado assunto podem observar mais detalhes de um evento do que aqueles mais experientes. Esta é uma das colunas em que este trabalho se suporta: desenvolvimento de método de estudo de mecanismos de reações químicas por alunos de ensino médio de escolas públicas de São Paulo, através da criação de animações.

Ao longo dos anos foi-se aprimorando um método baseado na abordagem de ensino orientado a problemas (estudo pela busca de solução de um 
problema colocado). As reações são apresentadas aos alunos através de experimentos reais efetuados no laboratório e da hipótese mecanística aceita na literatura. Trabalham então na confecção de uma animação das imagens 3D das superfícies de densidade eletrônica das interações dos reagentes indo para os produtos. As animações permitem análises termodinâmicas e cinéticas e as justificativas para aquele mecanismo. As substituições por átomos ou grupos diferentes dos encontrados na literatura propiciam discussões muito profícuas e num nível assombroso.

Atualmente a criação de vídeos de animação enseja o estudo de aspectos complexos do assunto. As imagens 3D de superfícies de densidade eletrônica dos reagentes interagindo até a formação dos produtos permitem exercitar o modus operandi científico em suas várias etapas, desde a proposição até a análise crítica de hipóteses, usando modelos quânticos e princípios de termodinâmica e cinética químicas. A sequência abaixo ilustra esse dinamismo das animações.

A animação aborda intuitivamente, através do impacto visual, conceitos básicos e abstratos de alta complexidade. O trabalho de confecção de animações dos modelos moleculares de reagentes e sua evolução aos produtos, ao mesmo tempo que fascinam os estudantes, acabam por desconstruir a ideia de simples transformação. Os aspectos cinéticos e termodinâmicos das interações ficam evidentes e constroem um sólido arcabouço conceitual de Química, mostrando a complexidade e a beleza contidas nos processos que ocorrem ininterruptamente na natureza.

As primeiras tentativas que fizemos de usar animações de superfícies 3D de densidades eletrônicas tinham o propósito de criar materiais didáticos eficientes para ensino a distância (FARAH \& RABÓCZKAY, 1998). A apresentação desse material suscitou muito interesse e levou a esta proposta de ensino.

\section{Objetivos}

Tentando mudar o panorama do ensino de Química Orgânica e fazer valer a opinião de pessoas do nível de Heinrich Hauptmann, emitida há mais de sessenta anos, resolvemos envolver os alunos em projetos com o objetivo de esclarecer o aspecto dinâmico e o motivo e a maneira (mecanismo) pelos quais acontecem as reações químicas. Como os raciocínios envolvidos na sobreposição de volumes espaciais são simples, o desafio principal foi demonstrar que a capacidade de abstração das pessoas nas etapas finais do ensino médio é suficiente para entender o enfoque da teoria de orbitais moleculares e o aspecto cinético das reações químicas. A motivação principal é a confecção de animações de modelos moleculares das reações que ocorrem no mundo real.

\section{Metodologia}

As animações foram feitas por alunos de ensino médio que vêm sendo patrocinados pela Pró-Reitoria de Pesquisa da USP há cerca de cinco anos, e se contou com a participação de aproximadamente vinte alunos de escolas públicas. Usam-se o modelo de orbitais de fronteira e a teoria do orbital molecular, mapeando-se a densidade eletrônica e obtendo gráficos das superfícies moleculares; essas imagens são usadas na criação de animações 3D. Aulas experimentais são ministradas in vitro e in silico sobre animação de imagens, criação de inputs e interações intermoleculares. Essas aulas eram intercaladas com a distribuição de tarefas com prazos para término e discussão dos resultados. Os conceitos de modelo e realidade dos átomos e moléculas e processos foram exaustivamente trabalhados nessas atividades.

\section{Resultados}

A avaliação foi efetuada através da verificação de aderência a cinco tópicos conceituais: 1) a reação é um processo contínuo no tempo; 2) as moléculas não existem fora do estado de iniciais (reagentes) e finais (produtos); 3) a reação é fruto de uma forte interação intermolecular através dos orbitais moleculares da periferia das moléculas; 4) a energia do processo é que determina seu andamento; 5) os elétrons são remanejados em novos 

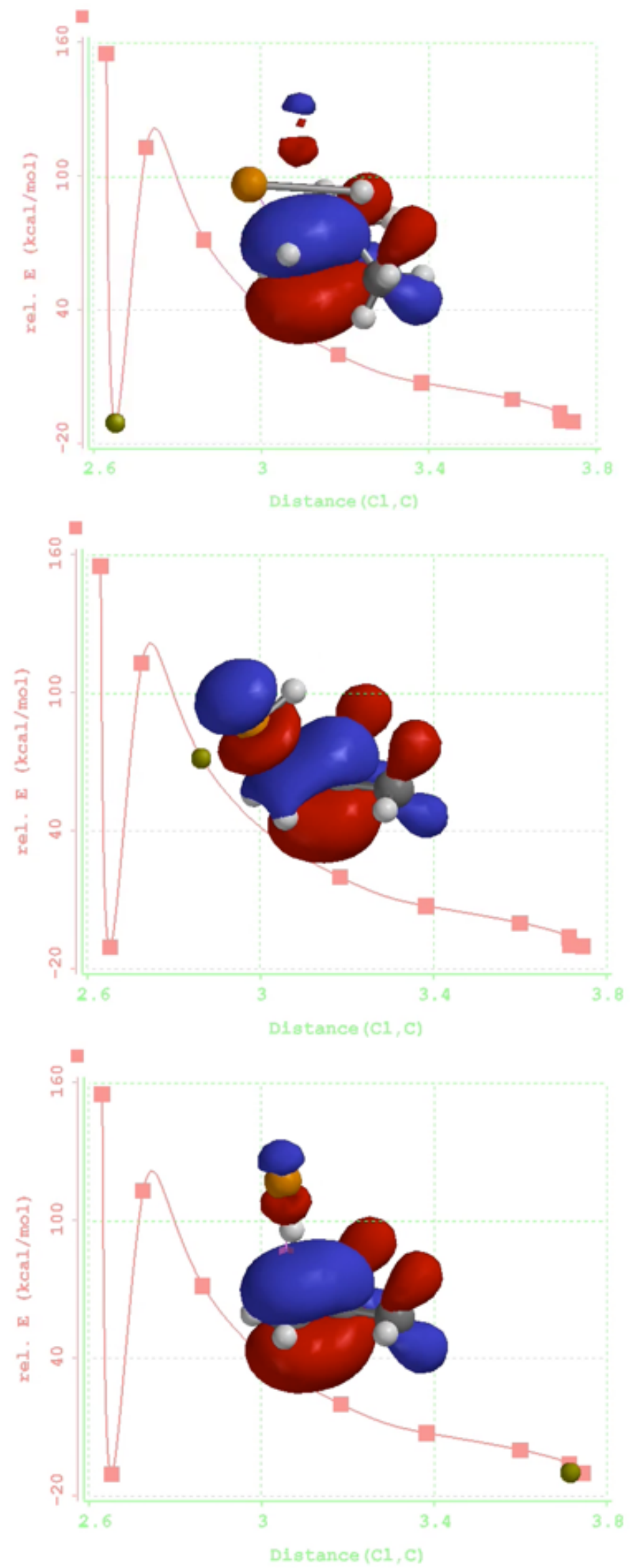

Figura 1 - Alguns frames obtidos para a animação de uma proposta mecanística simples. Os gráficos mostram a energia eletrônica relativa versus a distância C... C1. São apresentadas as superfícies de HOMO e LUMO com as fases em vermelho e azul. Para cada ponto do gráfico existe um frame e as imagens podem ser animadas com velocidade controlada. 
orbitais moleculares de modo a diminuir a energia em relação aos orbitais iniciais.

Apesar do reduzido número de alunos, os resultados das avaliações são consistentes: seis (cerca de 30\%) conseguiram trabalhar e adquirir os conceitos básicos, oito alunos (40\%) conseguiram adquirir até três (sempre os de número 1, 3 e 5), e os seis alunos restantes (30\%) não construíram os alicerces necessários para esse trabalho teórico, em parte devido às dificuldades na interface com os cálculos, entre outros motivos. Todos mostraram muito interesse nas demonstrações práticas que antecediam os trabalhos com modelos.

Pode-se comparar esse resultado ao obtido através da prática da docência desses assuntos nos cursos de graduação ao longo de mais de trinta anos usando os métodos tradicionais de sala de aula, que produziram resultados entre 5 e $11 \%$ de alunos no primeiro grupo descrito acima (30\%).

Mesmo considerando que os alunos de ensino médio optaram por este projeto - diferentemente dos da graduação, para os quais as disciplinas são obrigatórias - e que a atenção dada a cerca de quatro alunos por ano é muito maior do que numa sala com um total entre quarenta e oitenta alunos num semestre, o principal objetivo foi atingido: os enfoques mais modernos de Química Quântica podem ser abordados no ensino básico de reações e mecanismos de Química Orgânica.

Esses resultados sugerem alguns pontos que julgamos destacáveis: 1) um input complexo é essencial para desencadear os processos de formação de conceitos (não foram feitas simplificações conceituais nos assuntos abordados: modelo e teoria científica, dualidade partícula-onda, princípio da incerteza, observável como média, estrutura do átomo de hidrogênio, princípio variacional e campo autoconvergente etc.); 2) quanto mais densa a quantidade de informação dada (quantidade de informação que exige interpretação no menor tempo possível), maior a demanda por conceitos criada; 3) essa demanda deve ser cuidadosamente administrada de modo a permitir reformulá-la à luz de novas ideias e nunca pela simples descrição do conceito. O primeiro item foi atendido considerando que o input gerado pela visualização 3D animada é de alta densidade de informação; para promover alta demanda conceitual descrita no segundo item, foi adotado o método construtivista de apresentação de problemas e prazos para serem resolvidos. Finalmente, a discussão das respostas foi o ponto mais delicado e no qual o progresso do estudante pode ser avaliado ao longo da série de animações produzida.

\section{Referências Bibliográficas}

FARAH, J. P. S. \& RABÓCZKAY, T. "Democratização do Conhecimento: Educação Não Formal e Educação a Distância em Química". V Congresso International de Educação a Distância-Abed, São Paulo, 1998.

FARIAS, Robson F. de; NEVES, Luiz S. das \& SILVA, Denise D. da. História da Química no Brasil. São Paulo: Editora Átomo, 2004, pp. 64-65.

HALFORD, Bethany. "Is There a Crisis in Organic Chemistry Education?". Chemical and Engineering News, vol. 94, n. 13, pp. 24-25, 2016.

HAUPTMANN, Heinrich. Mecanismos de Reações Orgânicas. Rio de Janeiro: Agir, 1955.

INGOLD, Christopher K. "Principles of an Electronic Theory of Organic Reactions". Chem. Rev., vol. 15, n. 2, pp 225-274, 1934.

Structure and Mechanism in Organic Chemistry.

London: G Bell and Sons, 1953.

ROQUE, Nidia Franca. Substâncias Orgânicas: Estrutura e Propriedades. São Paulo: Edusp, 2011. 